\title{
Effect of aortic pericardial valve choice on outcomes and left ventricular mass regression in patients with left ventricular hypertrophy
}

\author{
Fraser D. Rubens, MD, MSc, FACS, FRCSC, ${ }^{a}$ Yen-Yen Gee, BA, ${ }^{a}$ Janet M. C. Ngu, MD, ${ }^{a}$ Li Chen, MSc,
} and Ian G. Burwash, MD, FRCPC

\section{ABSTRACT}

Objectives: We sought to assess the effect of 2 contemporary pericardial valves on left ventricular mass regression and clinical outcomes after aortic valve replacement (AVR) in patients with aortic stenosis (AS).

Methods: Patients were followed postoperatively in a dedicated valve clinic. A propensity score was derived for each patient and used to adjust all analyses. Longitudinal analysis was performed using a repeated measures growth curve model. Survival analysis was assessed with a Cox proportional hazards model.

Results: Since February 2011, 258 patients with AS and left ventricular hypertrophy underwent AVR with the Trifecta (TR) (St Jude Medical, St Paul, Minn) or Perimount Magna Ease (ME) (Edwards LifeSciences, Irvine, Calif) bioprosthesis. There were longer bypass and crossclamp times and the indexed left ventricular outflow tract was smaller in the TR group. For the TR and ME, respectively, peak $(14.4 \pm 5.1 \mathrm{~mm} \mathrm{Hg}$ vs $20.9 \pm 7.2 \mathrm{~mm} \mathrm{Hg} P<.001)$ and mean $(7.3 \pm 2.7 \mathrm{~mm} \mathrm{Hg}$ vs $10.9 \pm 4.3 \mathrm{~mm} \mathrm{Hg} ; P<.001)$ gradients were significantly smaller postoperatively in the TR group. There was greater total mass regression $\left(44.3 \mathrm{~g} / \mathrm{m}^{2} ; 95 \%\right.$ confidence interval [CI], 36.3-52.3 vs $29.5 ; 95 \% \mathrm{CI}, 20.4-$ $\left.38.5 \mathrm{~g} / \mathrm{m}^{2} ; P=.020\right)$ and mass regression over time in the TR group compared with the ME group $(P=.016)$. Freedom from readmission, congestive heart failure, and the composite outcome of all-cause mortality, readmission, and congestive heart failure at 2.5 years was significantly improved in the TR group (composite outcome in TR and ME groups, respectively, 90.2; 95\% CI, 81.994.9 and $78.2 ; 95 \% \mathrm{CI}, 67.1-86.0 ; P=.013)$

Conclusions: TR use was associated with significantly increased left ventricular mass regression and improved intermediate-term clinical outcome in patients with left ventricular hypertrophy undergoing AVR for AS, compared with use of the ME. (J Thorac Cardiovasc Surg 2016;152:1291-8)

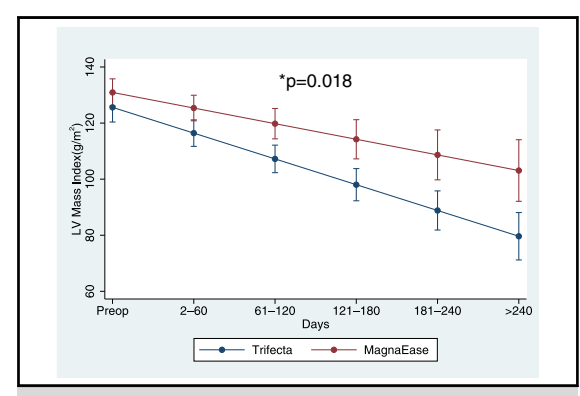

Postaortic valve replacement LV mass regression over time in patients receiving the Trifecta valve versus the Magna Ease valve.

\section{Central Message}

Use of the Trifecta valve results in greater left ventricular mass regression and improved outcomes compared with use of the Magna Ease valve in patients with aortic stenosis and left ventricular hypertrophy.

\section{Perspective}

This study demonstrates superior overall left ventricular mass regression and left ventricular mass regression over time with the Trifecta valve as well as improved freedom from the composite outcome of death, heart failure, and readmission compared with the Magna Ease valve at 2.5 years. The Trifecta valve should be strongly considered in patients with preoperative left ventricular hypertrophy undergoing aortic valve replacement.

See Editorial Commentary page 1299.
Growth of the elderly population has led to a dramatic increase in the number of patients presenting for aortic valve replacement (AVR). A large proportion of these patients

\footnotetext{
From the Departments of a Cardiac Surgery and ${ }^{\mathrm{c}}$ Cardiology, and ${ }^{\mathrm{b}}$ Cardiovascular Research Methods Center, University of Ottawa Heart Institute, Ottawa, Ontario, Canada.

Received for publication Dec 10, 2015; revisions received May 22, 2016; accepted for publication June 9, 2016; available ahead of print July 13, 2016.

Address for reprints: Fraser D. Rubens, MD, MSc, FACS, FRCSC, Department of Cardiac Surgery, University of Ottawa Heart Institute, 40 Ruskin St, Ottawa, Ontario K1Y 4W7, Canada (E-mail: frubens@ottawaheart.ca). $0022-5223 / \$ 36.00$

Copyright (c) 2016 by The American Association for Thoracic Surgery http://dx.doi.org/10.1016/j.jtcvs.2016.06.008
}

will have left ventricular hypertrophy (LVH), which is a strong predictor of worse outcome after AVR. ${ }^{1,2}$ A therapeutic goal of valve replacement is to enhance regression of left ventricular (LV) mass because this change has been associated with improved long-term survival.

Scanning this QR code will take you to a video, supplemental figures, and table for the article.

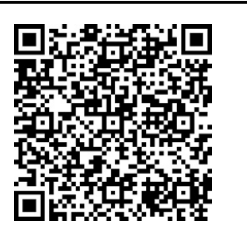




$$
\begin{aligned}
& \text { Abbreviations and Acronyms } \\
& \text { AS }=\text { aortic stenosis } \\
& \text { AVR }=\text { aortic valve replacement } \\
& \text { LV }=\text { left ventricular } \\
& \text { LVH }=\text { left ventricular hypertrophy } \\
& \text { LVMI }=\text { left ventricular mass index } \\
& \text { ME }=\text { Magna Ease valve } \\
& \text { PPM }=\text { patient prosthesis mismatch } \\
& \text { TR }=\text { Trifecta valve }
\end{aligned}
$$

Pericardial tissue valves are a popular option for valve replacement. The Perimount valve (Edwards LifeSciences, Irvine, Calif) is among the most frequently implanted bioprostheses worldwide. Previous iterations of this valve have demonstrated robust durability; however, their use has been associated with an increased incidence of patient-prosthesis mismatch (PPM). ${ }^{4}$ The Perimount Magna Ease valve (Edwards LifeSciences) (ME) was introduced to address this issue by having a supraannular design to theoretically decrease intraannular obstruction and thus decrease transprosthetic gradients.

The Trifecta valve (St Jude Medical, St Paul, Minn) (TR) is also designed for supraannular implantation. The leaflets of the TR are wrapped externally to maximize valve opening, thus increasing the orifice area and potentially decreasing the risk of PPM. Studies to date have confirmed excellent hemodynamic performance ${ }^{5}$; however, superior effects on LV mass regression or definitive clinical benefits have not been demonstrated.

The first objective of this study was to determine whether improvements in hemodynamic performance after AVR are associated with greater degrees of LV mass regression in patients with aortic stenosis (AS) and LVH. The second objective was to determine whether positive changes in valve performance are associated with improved intermediateterm clinical outcomes. We hypothesized that implantation of a TR would be an independent predictor of improved LV mass regression and intermediate-term clinical outcomes compared with those patients undergoing AVR with the ME prosthesis.

\section{METHODS}

\section{Study Design}

This was a retrospective cohort study of prospectively collected clinical data. We used the Strengthening the Reporting of Observational Studies in Epidemiology criteria ${ }^{6}$ for reporting of this observational trial.

\section{Setting}

Patients were identified who had undergone tissue AVR using either the TR or the ME valves between February 28, 2011, and April 8, 2015. All patients undergoing valve surgery were assessed annually in a dedicated valve surgery clinic. The database captures detailed information on preoperative, periprocedural, and postoperative variables for all patients

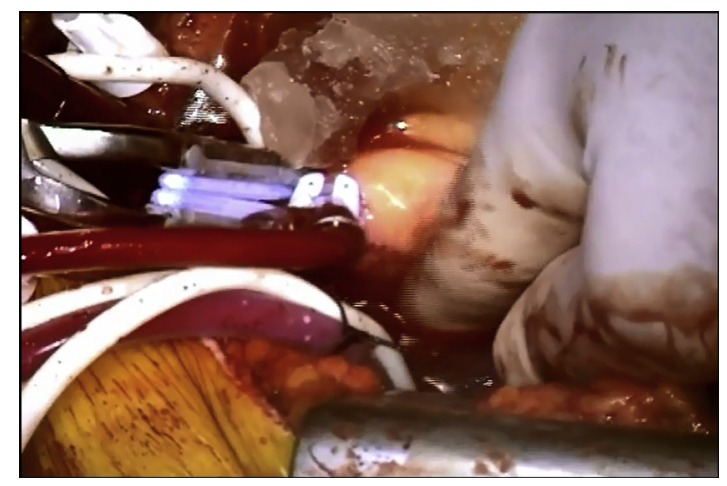

VIDEO 1. Surgical implantation steps for the implantation of a Trifecta $23 \mathrm{~mm}$ bioprosthesis (St Jude Medical, St Paul, Minn) in a 63-year-old male patient with severe aortic stenosis and a bicuspid valve. Video available at: http://www.jtcvsonline.org/article/S0022-5223(16)30542-6/addons.

undergoing valve surgery and is maintained by a team of full-time data abstractors who are responsible for data collection. For patients lost to followup, the electronic medical record was reviewed to document recent visits and dates and the family physician or cardiologist contacted where possible. Results from all postoperative echocardiograms, including those completed at other institutions, were collected. Echocardiograms $<2$ days from surgery were excluded. Results were audited by randomly double checking $10 \%$ of reports. The University of Ottawa Heart Institute has approval from its institutional research ethics board to anonymously publish data that are prospectively collected from the valve surgery clinic. Only data from patients who provided consent to allow confidential use of their clinical information were used.

\section{Participants}

Patients were included if the primary indication for AVR was AS and they had evidence of $\mathrm{LVH}$ on the preoperative echocardiogram (LV mass index $[$ LVMI $] \geq 115 \mathrm{~g} / \mathrm{m}^{2}$ in men, LVMI $\geq 95 \mathrm{~g} / \mathrm{m}^{2}$ in women). ${ }^{7}$ Patients were also included in cases in which LV mass could not be calculated due to missing indices, if the echocardiographer indicated specifically that there was evidence of LVH. Patients were excluded from analysis if they underwent AVR primarily for aortic insufficiency, or if they underwent concomitant mitral valve repair or replacement. After all exclusions, there were 117 patients in the TR group and 141 patients in the ME group.

\section{Operative Procedures}

This was a concurrent series and valve choice was based on surgeon preference. Both aortic valves were implanted in the supraannular position by the use of either interrupted 2-0 polyester or horizontal mattress sutures of 2-0 polyester with pledgets on the ventricular aspect. Myocardial protection was provided using either antegrade or retrograde cold $\left(4^{\circ} \mathrm{C}\right)$ blood cardioplegia according to surgeon preference (Video 1).

\section{Variables}

The primary outcomes included LV mass regression over time as well as the composite outcome of all-cause death, heart failure requiring physician intervention, and readmission to hospital for cardiac care. Secondary outcomes included total LV mass regression, time to all-cause death, time to cardiac readmission, time to heart failure requiring physician intervention, and the composite outcome of all-cause death and first cardiac readmission. Heart failure was identified from the patient record as a new event in which the diagnosis of worsened congestive heart failure was confirmed by the treating physician and in which the patient was successfully treated with diuresis. Mismatch was calculated using values that had been derived 
TABLE 1. Preoperative patient characteristics with difference adjusted with derived propensity score

\begin{tabular}{|c|c|c|c|c|c|}
\hline \multirow[b]{2}{*}{ Variable } & \multirow[b]{2}{*}{ Matching } & \multicolumn{2}{|c|}{ Mean } & \multirow[b]{2}{*}{$P$ value } & \multirow[b]{2}{*}{ Standardized difference } \\
\hline & & Trifecta* & Magna Ease $\dagger$ & & \\
\hline \multirow[t]{2}{*}{$\%$ Male } & $\mathrm{U}$ & 0.50 & 0.62 & .069 & -0.225 \\
\hline & M & 0.53 & 0.52 & .954 & \\
\hline \multirow[t]{2}{*}{ Age (y) } & $\mathrm{U}$ & 73.2 & 72.6 & .673 & 0.096 \\
\hline & M & 73.4 & 73.8 & .757 & \\
\hline \multirow[t]{2}{*}{ Low ejection fraction $(\%)$} & $\mathrm{U}$ & 23.9 & 23.4 & .921 & 0.099 \\
\hline & M & 25.8 & 25.4 & .962 & \\
\hline \multirow[t]{2}{*}{ Atrial fibrillation (\%) } & $\mathrm{U}$ & 17.9 & 15.6 & .616 & 0.031 \\
\hline & M & 14.0 & 12.9 & .835 & \\
\hline \multirow[t]{2}{*}{ Syncope $(\%)$} & $\mathrm{U}$ & 4.2 & 3.5 & .616 & 0.104 \\
\hline & M & 4.8 & 5.4 & .519 & \\
\hline \multirow[t]{2}{*}{ Endocarditis (\%) } & $\mathrm{U}$ & 3.4 & 2.1 & .527 & 0.108 \\
\hline & M & 0.0 & 0.0 & .602 & \\
\hline \multirow[t]{2}{*}{ Reoperation $(\%)$} & $\mathrm{U}$ & 5.1 & 2.8 & .344 & -0.044 \\
\hline & M & 1.1 & 1.4 & .824 & \\
\hline \multirow[t]{2}{*}{ Moderate-severe tricuspid regurgitation ( $\%)$} & $\mathrm{U}$ & 5.1 & 6.4 & .670 & 0.002 \\
\hline & M & 6.5 & 8.1 & .675 & \\
\hline \multirow[t]{2}{*}{ Syncope } & $\mathrm{U}$ & 4.3 & 3.5 & .764 & 0.104 \\
\hline & M & 5.4 & 4.0 & .666 & \\
\hline \multirow[t]{2}{*}{ Urgent/emergent $(\%)$} & $\mathrm{U}$ & 34.5 & 27.3 & .219 & 0.132 \\
\hline & M & 32.3 & 28.5 & .577 & \\
\hline \multirow[t]{2}{*}{ Coronary disease $(\%)$} & $\mathrm{U}$ & 49.6 & 48.2 & .830 & 0.033 \\
\hline & M & 49.5 & 48.1 & .859 & \\
\hline \multirow[t]{2}{*}{ Body surface area $\left(\mathrm{m}^{2}\right)$} & $\mathrm{U}$ & 1.91 & 1.92 & 605 & -0.109 \\
\hline & M & 1.90 & 1.90 & .955 & \\
\hline \multirow[t]{2}{*}{ Cerebrovascular disease $(\%)$} & $\mathrm{U}$ & 7.0 & 5.7 & .672 & 0.075 \\
\hline & M & 6.5 & 9.2 & .493 & \\
\hline \multirow[t]{2}{*}{ Peripheral vascular disease $(\%)$} & $\mathrm{U}$ & 11.4 & 10.7 & .862 & 0.050 \\
\hline & M & 11.8 & 10.1 & .705 & \\
\hline \multirow[t]{2}{*}{ Smoker } & $\mathrm{U}$ & 4.3 & 10.6 & .057 & -0.228 \\
\hline & M & 5.4 & 6.2 & .821 & \\
\hline \multirow[t]{2}{*}{ Diabetes } & $\mathrm{U}$ & 32.5 & 37.9 & .373 & -0.141 \\
\hline & M & 34.4 & 33.1 & .860 & \\
\hline \multirow[t]{2}{*}{ Chronic obstructive pulmonary disease } & $\mathrm{U}$ & 17.5 & 15.7 & 698 & 0.094 \\
\hline & M & 19.4 & 16.7 & .640 & \\
\hline \multirow[t]{2}{*}{ Serum creatinine $(\mu \mathrm{mol} / \mathrm{L})$} & $\mathrm{U}$ & 97.0 & 107.9 & .270 & -0.127 \\
\hline & M & 98.8 & 103.0 & .696 & \\
\hline
\end{tabular}

$U$, Unmatched; $M$, matched. *St Jude Medical, St Paul, Minn. †Edwards LifeSciences, Irvine, Calif.

from in vivo calculations of effective orifice area from a clinical study of the Perimount Magna valve (Edwards LifeSciences), which was the precursor of the $\mathrm{ME},{ }^{8}$ and from premarket approval data on the TR provided by the manufacturer that had been derived from in vivo studies in a prospective multicenter trial.

All patients were analyzed for time-to-event clinical outcomes. The median time of follow-up was 2.04 years (interquartile range [IQR], 1.06$2.94)$ in the TR group and 1.22 years (IQR, 0.71-1.98) in the ME group $(P<.001)$. The median number of postoperative echocardiograms was significantly greater in the TR group (2 [IQR, 2-5] in the TR group vs 2 [IQR, 2-4] in the ME group) $(P=.013)$.

\section{Statistical Analysis}

Continuous variables were reported as mean \pm standard deviation for normally distributed or median and IQR for nonnormally distributed continuous variables. Normality was tested using tests for skewness and kurtosis. Categorical variables were reported as counts and percentages.
Student $t$ tests or Wilcoxon rank-sum tests were used to compare continuous variables between the 2 valve groups. For categorical variables, $\chi^{2}$ or Fisher exact tests were used to compare the differences between the 2 groups.

To minimize the confounding effects in this nonrandomized observational study, propensity score adjustments were applied to take into account differences in population demographic characteristics between the 2 valve groups. Propensity scores were calculated using a logistic regression model in which the group indicator (TR vs ME) was the dependent variable, and all of the key preoperative demographic variables where there was no collinearity were entered in the model as independent variables. Lists of the variables used in the propensity score calculation and the standardized differences after matching are presented in Tables 1 and 2. Figure E1 displays the summary of the covariate imbalance via a dot chart with a standardized bias for each covariate. Multiple imputation was applied to continuous variables with $>10 \%$ missing (LV end-diastolic and endsystolic diameter, interventricular septal diameter, posterior wall thickness, and LV outflow tract diameter) before being used in the propensity score derivation. All analyses were performed with adjustment for the propensity 
TABLE 2. Preoperative echocardiographic characteristics with difference adjusted for derived propensity score

\begin{tabular}{|c|c|c|c|c|c|}
\hline \multirow[b]{2}{*}{ Variable } & \multirow[b]{2}{*}{ Matching } & \multicolumn{2}{|c|}{ Mean } & \multirow[b]{2}{*}{$P$ value } & \multirow[b]{2}{*}{ Standardized difference } \\
\hline & & Trifecta* $^{*}(n=114)$ & Magna Ease $\nmid(n=141)$ & & \\
\hline \multirow[t]{2}{*}{ LVOTi $\left(\mathrm{cm} / \mathrm{m}^{2}\right)$} & $\mathrm{U}$ & 1.14 & 1.17 & .042 & -0.225 \\
\hline & M & 1.14 & 1.14 & .865 & \\
\hline \multirow[t]{2}{*}{ AVAi $\left(\mathrm{cm}^{2} / \mathrm{m}^{2}\right)$} & $\mathrm{U}$ & 0.40 & 0.44 & .054 & -0.221 \\
\hline & M & 0.40 & 0.40 & .986 & \\
\hline \multirow[t]{2}{*}{ Left ventricular end-diastolic diameter $(\mathrm{cm})$} & $\mathrm{U}$ & 5.11 & 5.12 & .880 & 0.017 \\
\hline & M & 5.13 & 5.13 & .964 & \\
\hline \multirow[t]{2}{*}{ Left ventricular end-systolic diameter $(\mathrm{cm})$} & $\mathrm{U}$ & 3.43 & 3.48 & .669 & 0.008 \\
\hline & M & 3.49 & 3.47 & .896 & \\
\hline \multirow[t]{2}{*}{ Indexed aortic root $\left(\mathrm{cm} / \mathrm{m}^{2}\right)$} & $\mathrm{U}$ & 1.69 & 1.74 & .152 & -0.128 \\
\hline & M & 1.69 & 1.70 & .686 & \\
\hline \multirow[t]{2}{*}{ Peak gradient (mm Hg) } & $\mathrm{U}$ & 78.8 & 75.7 & .398 & 0.080 \\
\hline & M & 78.8 & 79.1 & .944 & \\
\hline \multirow[t]{2}{*}{ Interventricular septum (cm) } & $\mathrm{U}$ & 1.28 & 1.29 & .941 & -0.073 \\
\hline & M & 1.28 & 1.26 & .689 & \\
\hline \multirow[t]{2}{*}{ Posterior wall thickness $(\mathrm{cm})$} & $\mathrm{U}$ & 1.20 & 1.21 & .819 & -0.077 \\
\hline & M & 1.19 & 1.19 & .927 & \\
\hline \multirow{2}{*}{ Indexed left ventricular mass $\left(\mathrm{g} / \mathrm{m}^{2}\right)$} & $\mathrm{U}$ & 133.4 & 134.2 & .802 & -0.028 \\
\hline & M & 133.1 & 132.6 & .882 & \\
\hline
\end{tabular}

$\overline{L V O T i}$, Indexed left ventricular outflow tract diameter, $U$, unmatched; $M$, matched; $A V A i$, indexed aortic valve area. *St Jude Medical, St Paul, Minn. $\dagger$ Edwards LifeSciences, Irvine, Calif.

scores as well as operative characteristics (ie, pump time, anoxia time, maze procedure, and myomectomy) that were different between the 2 valve groups. Total LV mass regression (preoperative to lowest measured postoperative) was assessed using a linear regression model correcting for the propensity score. Changes over time between the 2 groups of LV mass regression, peak, and mean gradients (postimplantation) and LV endsystolic and end-diastolic diameter were assessed by adjusting for the propensity scores and operative characteristics using a repeated measures growth curve model that treated the within-group effect of time as a continuous variable, the treatment group (TR vs ME), and an interaction term (treatment time) as a fixed effect along with random intercept assuming that missing data are missing at random. Kaplan-Meier survival curves were generated for survival data. Cox proportional hazards regression models were used for time-to-event outcomes adjusting for the propensity score and operative characteristics. Cardiac readmission and congestive heart failure events requiring urgent intervention were treated as multiple failure-time data using a conditional risk set model. The proportionality assumption of the Cox proportional hazards regression model was tested using plots of $-\log (-\log$ survival) versus $\log$ (analysis time). All statistical analyses and plots were performed with Stata version 14.1 (StataCorp, College Station, Tex).

\section{RESULTS \\ Participants}

The patient enrollment algorithm is indicated in Figure E2. Patient characteristics of the 2 groups are listed in Table 1. The majority $(97 \%)$ of patients had intrinsic valve disease, whereas 4 patients presented with bacterial endocarditis (1 in the TR group and 3 in the ME group). Preoperative echocardiographic measurements are presented in Table 2. Key differences included smaller aortic roots in the TR group $(P=.034)$ as reflected by smaller indexed LV outflow tract $(P=.042)$ and smaller aortic valve area $(P=.028)$.

Operative characteristics of the 2 groups are listed in Table 3. The TR group had longer mean cardiopulmonary bypass times $(P=.003)$ and anoxia times $(P=.044)$.

The incidence of predicted moderate PPM (indexed aortic valve area $\leq 0.85 \mathrm{~cm}^{2} / \mathrm{m}^{2}$ ) was $23.1 \%$ in the TR group, whereas it was $0.7 \%$ in the ME group $(P<.001)$ and no patients were predicted to have severe mismatch. The distribution of valve sizes in the 2 groups is illustrated in Figure E3. Small valves (sizes 19 and 21) were significantly more common in the TR group $(39.4 \%$ in the TR group vs $21.9 \%$ in the ME group) $(P=.001)$.

\section{Postoperative Complications}

Early (30-day) complications are presented in Table E1. Moderate or greater tricuspid insufficiency was seen in

TABLE 3. Operative characteristics

\begin{tabular}{lccc}
\hline \multicolumn{1}{c}{ Variable } & $\begin{array}{c}\text { Trifecta* } \\
(\mathbf{n}=\mathbf{1 1 4})\end{array}$ & $\begin{array}{c}\text { Magna Ease } \\
(\mathbf{n}=\mathbf{1 4 1})\end{array}$ & $\boldsymbol{P}$ value \\
\hline Grafts & $2(1-3)$ & $2(1-2)$ & .641 \\
Cardiopulmonary bypass time & $124.0 \pm 49.2$ & $106.8 \pm 41.2$ & .003 \\
Anoxia time & $85.4 \pm 26.4$ & $78.4 \pm 28.8$ & .044 \\
Aortic root enlargement & $2(1.8)$ & $2(1.4)$ & .802 \\
Ascending aortic replacement & $8(7.3)$ & $9(6.4)$ & .781 \\
Maze procedure & $14(12.0)$ & $10(7.1)$ & .180 \\
Myomectomy & $6(5.1)$ & $2(1.4)$ & .087 \\
Tricuspid valve repair & $3(2.7)$ & $2(1.4)$ & .462 \\
\hline Values are presented as n (interquartile range), mean \pm standard deviation, or n $(\%)$. \\
*St Jude Medical, St Paul, Minn. $\dagger$ Edwards LifeSciences, Irvine, Calif.
\end{tabular}




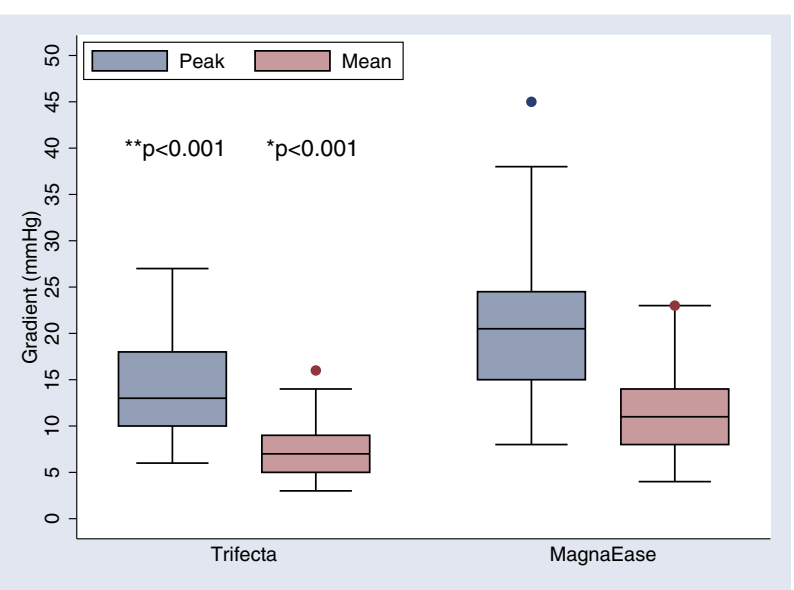

FIGURE 1. Echocardiographic gradients after aortic valve replacement. Both peak and mean gradients were decreased in the Trifecta valve (St Jude Medical, St Paul, Minn) group compared with the Perimount Magna Ease valve (Edwards LifeSciences, Irvine, Calif) group $(P<.001$ for both). In the boxplot, the top and bottom margins represent the first and third quartile and the line inside the box represents the second quartile (ie, the median). Whiskers represent upper and lower adjacent values.

$16.1 \%$ patients in the TR group versus $14.5 \%$ in the ME group $(P=.801)$. There was no difference in the incidence of severe tricuspid insufficiency $(3.2 \%$ in the TR group vs $3.0 \%$ in the ME group; $P=.931$ ). Postoperative aortic insufficiency of moderate or greater degree on at least 1 study was seen in $1.8 \%$ in the ME group and $2.6 \%$ in the TR group $(P=.756)$. There were no cases of paravalvular leak in either group.

\section{Echocardiographic Follow-up}

Peak $(P<.001)$ and mean $(P<.001)$ gradients were significantly smaller in the TR group compared with the ME group (Figure 1). There was no time-valve effect in either peak $(P=.137)$ or mean $(P=.201)$ gradients. There were significant decreases in LV end-systolic diameter and LV end-diastolic diameter with both valves, but the absolute changes in end-diastolic $(-0.66 \pm 0.77 \mathrm{~cm}$ in the TR group vs $-0.43 \pm 0.91 \mathrm{~cm}$ in the ME group; $P=.118$ ) and endsystolic dimensions $(-0.61 \pm 0.89 \mathrm{~cm}$ in the TR group vs $-0.48 \pm 0.72$ in the ME group; $P=.389$ ). There was no time-valve effect in either end-systolic $(P=.173)$ or enddiastolic $(P=.165)$ sizes. There was a significant decrease in right ventricular systolic pressure in both groups $(P<.001)$; however, the change was not different between groups $(9.9 \pm 13.8 \mathrm{~mm} \mathrm{Hg}$ in the TR group vs $5.7 \pm 12.5 \mathrm{~mm} \mathrm{Hg}$ in the ME group; $P=.184$ ).

Valve type was a significant predictor of total indexed LV mass regression in the linear regression model when adjusted for the propensity score $(P=.016)$. Marginal linear prediction of LV mass regression for the TR group was $45.5 \mathrm{~g} / \mathrm{m}^{2}$ (95\% confidence interval [CI], 38.1-53.0) versus the ME group at $28.3 \mathrm{~g} / \mathrm{m}^{2}(95 \% \mathrm{CI}, 19.6-37.0)$.

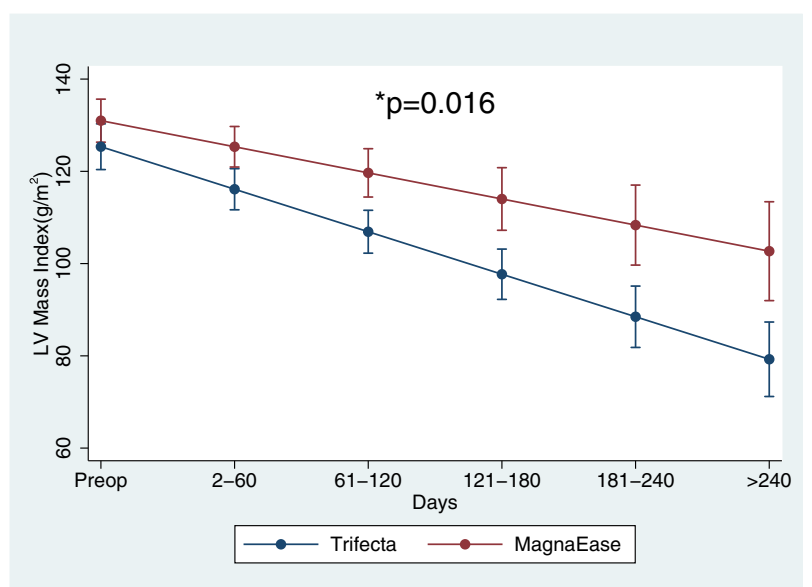

FIGURE 2. Changes in indexed left ventricle $(L V)$ mass over time after aortic valve replacement adjusted for propensity score and operative characteristics in the Trifecta Valve (St Jude Medical, St Paul, Minn) group compared with the Perimount Magna Ease valve (Edwards LifeSciences, Irvine, Calif) group. Presented are predicted margins with $95 \%$ confidence interval.

When LV mass regression was assessed over time using a repeated measures growth curve model, a significantly greater change in LVMI was observed in the TR group compared with the ME group $(P=.016)$ (Figure 2).

\section{Time-to-Event Data}

Time to all-cause death was not significantly related to valve type (TR) (hazard ratio [HR], 0.342; 95\% CI, $0.088-1.328 ; P=.121)$, whereas it was significantly related to a decreased risk of cardiac-related readmission (HR, $0.235 ; 95 \% \mathrm{CI}, 0.077-0.715 ; P=.011)$ and heart failure requiring urgent intervention (HR, $0.177 ; 95 \% \mathrm{CI}, 0.042$ $0.728 ; P=.016$ ).

Patients in the TR group had a significantly improved survival for the composite outcome of all-cause death, readmission, and heart failure (HR, $0.311 ; 95 \% \mathrm{CI}$, $0.122-0.791 ; P=.013)$ and all-cause death and readmission (HR, 0.320; 95\% CI, 0.126-0.809; $P=.024$ ) compared with patients in the ME group. Kaplan-Meier curves for the composite outcomes of all-cause death, readmission, and congestive heart failure are presented in Figure 3, $A-C$. The Kaplan-Meier curves for the composite outcomes of all-cause death, readmission, and heart failure and allcause death and readmission are presented in Figure 4, $A$ and $B$.

\section{DISCUSSION}

Implantation of the TR in patients with LVH was associated with significantly lower peak and mean gradients compared with implantation of the ME. Although the postoperative improvements in gradients in both groups were associated with decreases in LV end-systolic and enddiastolic dimensions and total LV mass regression, TR 

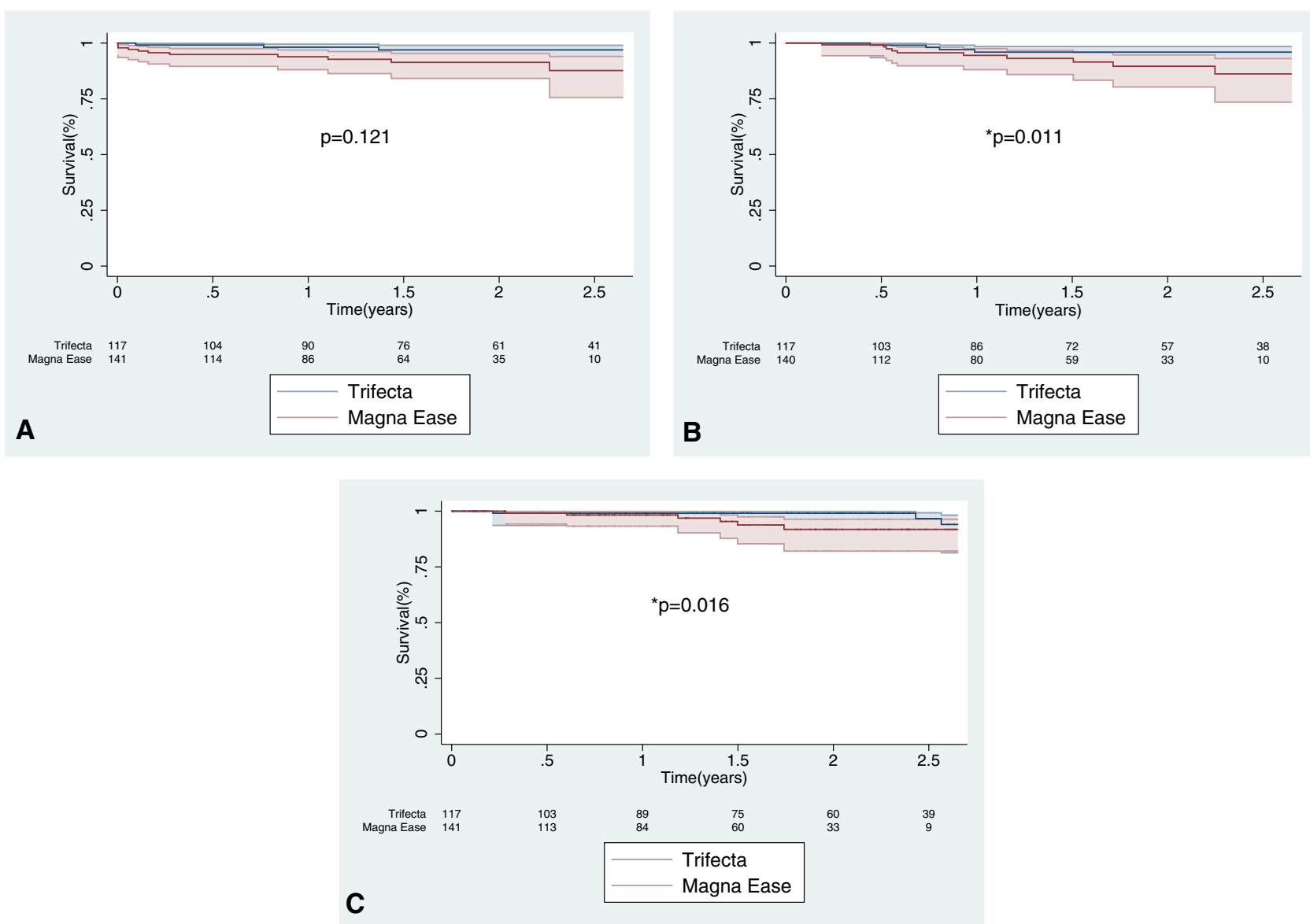

FIGURE 3. Freedom from outcomes adjusted for propensity score and operative characteristics in the Trifecta valve (St Jude Medical, St Paul, Minn) group compared with the Perimount Magna Ease valve (Edwards LifeSciences, Irvine, Calif) group. A, All-cause death. B, Readmission. C, Congestive heart failure.

use was a predictor of significantly greater indexed LV mass regression. No other factors were significantly related, including predicted PPM, low mean transvalvular gradient, and preoperative indexed LV mass. There was also a positive time-valve effect interaction of the TR with greater LV mass regression demonstrated in the repeated measures mixed-effects model when controlling for all differences in the 2 groups, including gender, cardiopulmonary bypass time, right ventricular systolic pressure, and indexed aortic root size. Freedom from the composite outcomes of all-cause death, readmission, and congestive heart failure and all-cause death and readmission, were decreased in AS patients with LVH undergoing TR implantation compared with implantation of the ME. Anoxia time was also a significant predictor of worse time-to-event survival for both composite outcomes. Anoxia time was a significant predictor of poor longterm survival after AVR with either valve.

Progressive LVH develops in a sizable proportion of patients with hemodynamically substantial AS. Chronic LV pressure overload causes both increases in myocardial mass and changes in LV geometry as compensatory mechanisms to reduce wall stress and maintain cardiac output. Secondary effects include decreased ventricular compliance and ischemia-induced myocardial fibrosis. ${ }^{10}$

LV mass regression and diastolic function recovery are therapeutic targets of AVR because ventricular remodeling is associated with improved mortality. ${ }^{2}$ In general, decreases in LV mass of between $17 \%$ and $31 \%$ are observed after AVR, ${ }^{2,11}$ with the largest decline seen within the first 3 months $^{2}$ and much smaller declines observed over the following years. However, regression of LVH after AVR is often incomplete and this may be a contributor to worse long-term outcomes. ${ }^{2} \mathrm{LV}$ mass regression will be less pronounced if residual transvalvular gradients are excessive, particularly in the presence of PPM. ${ }^{12}$

Other features that have been linked to failure of regression include the degree of preoperative $\mathrm{LVH}$, left atrial size, and LV systolic dysfunction. ${ }^{2}$ In the current study, multiple covariates, including the above 3 , were tested as possible predictors of LV mass regression. There was no relationship between the degree of mass regression and markers of chronicity such as the degree of LVH or left atrial size. We also did not demonstrate an effect of small valve size on the 


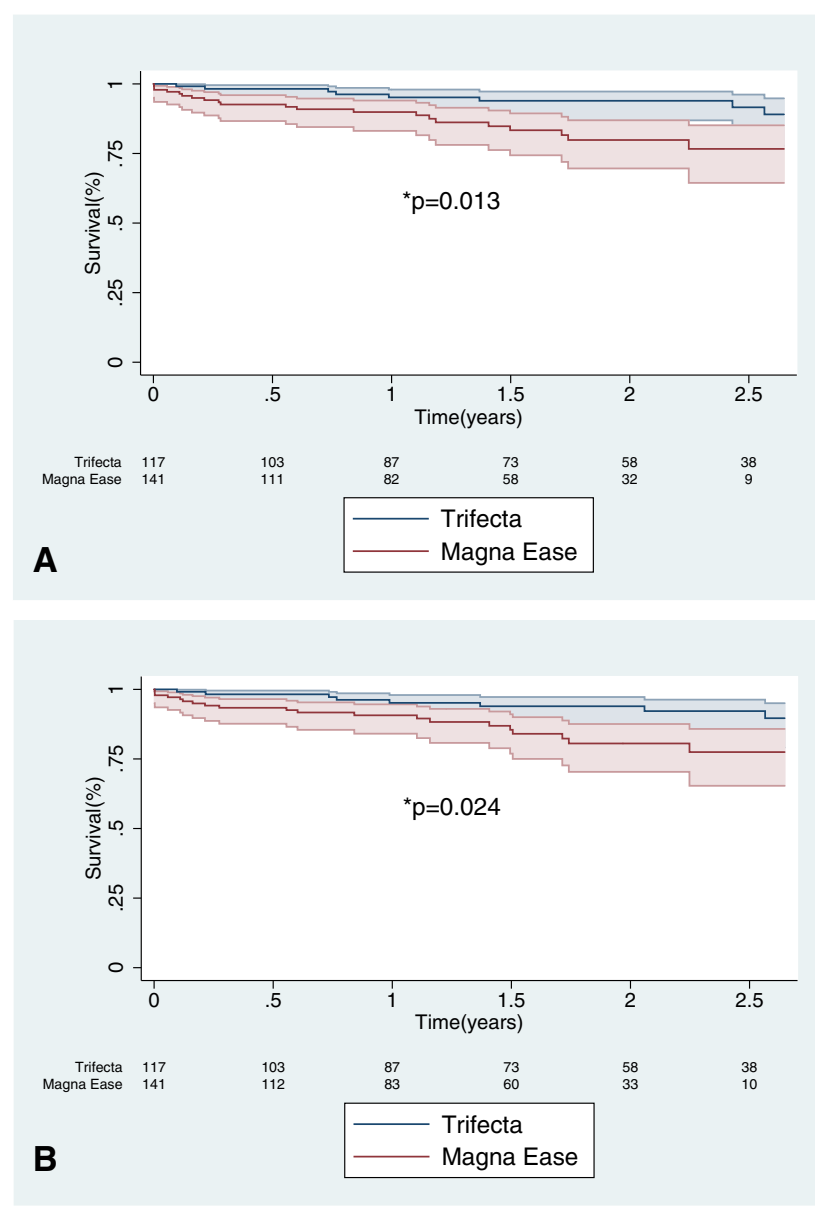

FIGURE 4. Freedom from composite outcomes adjusted for propensity score and operative characteristics in the Trifecta valve (St Jude Medical, St Paul, Minn) group compared with the Perimount Magna Ease valve (Edwards LifeSciences, Irvine, Calif) group. A, All-cause death, heart failure, and cardiac readmission. B, All-cause death and cardiac readmission.

degree of LV mass regression. In fact, smaller valve sizes were more frequently implanted in the TR group. The effect of gender on the degree of LVH regression was not significant $(P=.145)$.

Maximum LV mass regression occurred within 4 months, with no significant further regression identified in either group up to 2.5 years. Other studies have confirmed the rapid nature of LV mass regression, ${ }^{13}$ which can be demonstrated as soon as 1 month after intervention. These changes were associated with a decreased need for hospitalization for cardiac reasons. ${ }^{13}$

The TR is a low profile, stented pericardial tissue valve designed for supraannular placement. The valve leaflets are wrapped external to the stent, rather than mounted inside the stent, to minimize leaflet stress, maximize valve opening, ${ }^{14}$ and thereby potentially increasing the orifice area. Retrospective cohort studies have shown positive hemodynamic performance with the TR when compared with other contemporary bioprostheses. Findings have included lower mean gradients, greater effective orifice area, ${ }^{15,16}$ and a lower incidence of severe PPM $(1.3 \%$ in the TR group vs $3.2 \%$ in the Perimount group). ${ }^{16}$ To address the confounding issues of patient variability in past retrospective cohort studies, we completed a matched-paired comparative analysis, and demonstrated that the improved hemodynamic performance of the TR was associated with a significant improvement in stroke volume and indexed effective orifice areas. ${ }^{17}$ We believe the current trial supports these positive findings that were shown in the matched-paired design.

Surgeons were comfortable with the Perimount Magna because of the good medium- and long-term outcomes of this valve and its precursors, as well as the evidence of excellent durability up to 15 years, despite a potential rate of severe PPM reported to be up to $28 \%{ }^{18}$ It has been proposed that the ME will have similar durability and this has been supported by extensive in vitro testing. ${ }^{19}$ The longterm durability of the TR has not yet been demonstrated, although 2-year results from 1014 TR implants in 31 centers have documented an excellent freedom from valve explant of $99.4 \%{ }^{5}$ There are no data to date suggesting concerns with longer-term implantation.

The current study, as well as our previous work ${ }^{17}$ raises concerns about potential inaccuracies of the effective orifice areas available in the literature ${ }^{8}$ and those provided by industry. ${ }^{9}$ Based on the differences in hemodynamic performance seen with the 2 valves, it is our impression that the values reported for the $\mathrm{ME}^{8}$ may overestimate the actual effective orifice areas. On the other hand, the actual effective orifice areas for the TR may be underestimated, as we previously demonstrated. ${ }^{17}$

This study is limited because the results are from a single large referral center. There may have been some referral bias because the cases in the TR group were more frequently small women with small aortic roots. On the other hand, this group would be expected to be at higher risk, and insertion of a smaller valve size would theoretically inhibit LV mass regression. ${ }^{20}$ These outcomes were not seen. Also, in vivo effective orifice area measurements were not available in our patients. This would have allowed more investigation as to the relationship between PPM and mass regression. Finally, we did not analyze the influence of implantation technique as an independent factor in postoperative hemodynamic performance after AVR. We previously demonstrated in a similar study that the use or nonuse of subannular pledgets did not influence valve hemodynamic performance. ${ }^{17}$ Recent work by Tabata and colleagues ${ }^{21}$ has supported that an interrupted nonpledget technique may be associated with a lower incidence of patient-prosthesis mismatch due to a relatively larger increase in effective orifice area. Therefore, the importance of this factor should be assessed in further work. 


\section{CONCLUSIONS}

These study results have demonstrated that significant improvements in the transvalvular hemodynamic performance of the TR (compared with the ME) is associated with improved LV mass regression. TR implantation was also associated with a significant improvement in freedom from the composite outcome of all-cause death, readmission, and heart failure. Further studies are necessary to confirm whether the clinical benefits are sustained and whether they are balanced by reasonable durability of the TR.

\section{Conflict of Interest Statement}

Authors have nothing to disclose with regard to commercial support.

\section{References}

1. van Straten AH, Soliman Hamad MA, Peels KC, van den Broek KC, ter Woorst JF, Elenbaas TW, et al. Increased septum wall thickness in patients undergoing aortic valve replacement predicts worse late survival. Ann Thorac Surg. 2012:94:66-71.

2. Beach JM, Mihaljevic T, Rajeswaran J, Marwick T, Edwards ST, Nowicki ER, et al. Ventricular hypertrophy and left atrial dilatation persist and are associated with reduced survival after valve replacement for aortic stenosis. J Thorac Cardiovasc Surg. 2014;147:362-9.e8.

3. Ali A, Patel A, Ali Z, Abu-Omar Y, Saeed A, Athanasiou T, et al. Enhanced left ventricular mass regression after aortic valve replacement in patients with aortic stenosis is associated with improved long-term survival. J Thorac Cardiovasc Surg. 2011;142:285-91.

4. Clavel MA, Webb JG, Pibarot P, Altwegg L, Dumont E, Thompson C, et al. Comparison of the hemodynamic performance of percutaneous and surgical bioprostheses for the treatment of severe aortic stenosis. J Am Coll Cardiol. 2009; 53:1883-91.

5. Bavaria JE, Desai ND, Cheung A, Petracek MR, Groh MA, Borger MA, et al. The St Jude Medical Trifecta aortic pericardial valve: results from a global, multicenter, prospective clinical study. J Thorac Cardiovasc Surg. 2014;147:590-7.

6. von Elm E, Altman DG, Egger M, Pocock SJ, Gotzsche PC, Vandenbroucke JP, et al. The Strengthening the Reporting of Observational Studies in Epidemiology (STROBE) statement: guidelines for reporting observational studies. Lancet. 2007;370:1453-7.

7. Lang RM, Badano LP, Mor-Avi V, Afilalo J, Armstrong A, Ernande L, et al. Recommendations for cardiac chamber quantification by echocardiography in adults: an update from the American Society of Echocardiography and the Euro- pean Association of Cardiovascular Imaging. J Am Soc Echocardiogr. 2015;28: 1-39.e14.

8. Botzenhardt F, Eichinger WB, Guenzinger R, Bleiziffer S, Wagner I, Bauernschmitt R, et al. Hemodynamic performance and incidence of patientprosthesis mismatch of the complete supraannular Perimount Magna bioprosthesis in the aortic position. Thorac Cardiovasc Surg. 2005;53:226-30.

9. Trifecta valve. Premarket approval application summary of safety and effectiveness data. St. Jude Medical FDA application; 2011.

10. Weidemann F, Herrmann S, Stork S, Niemann M, Frantz S, Lange V, et al. Impact of myocardial fibrosis in patients with symptomatic severe aortic stenosis. Circulation. 2009; 120:577-84.

11. Monrad ES, Hess OM, Murakami T, Nonogi H, Corin WJ, Krayenbuehl HP. Time course of regression of left ventricular hypertrophy after aortic valve replacement. Circulation. 1988;77:1345-55.

12. Kulik A, Burwash IG, Kapila V, Mesana TG, Ruel M. Long-term outcomes after valve replacement for low-gradient aortic stenosis: impact of prosthesis-patient mismatch. Circulation. 2006;114:I553-8.

13. Lindman BR, Stewart WJ, Pibarot P, Hahn RT, Otto CM, Xu K, et al. Early regression of severe left ventricular hypertrophy after transcatheter aortic valve replacement is associated with decreased hospitalizations. JACC Cardiovasc Intervent. 2014;7:662-73.

14. Bavaria JE. Point: access to transcatheter aortic valve replacement should be limited to high-volume surgical centers. J Thorac Cardiovasc Surg. 2013;145: 1441-3.

15. Maruyama M, Daimon M, Kawata T, Kasai T, Ichikawa R, Miyazaki S, et al. Early hemodynamic performance of the trifecta bioprosthetic valve in patients with aortic valve disease. Circulation. 2014;78:1372-8.

16. Ugur M, Suri RM, Daly RC, Dearani JA, Park SJ, Joyce LD, et al. Comparison of early hemodynamic performance of 3 aortic valve bioprostheses. J Thorac Cardiovasc Surg. 2014;148:1940-6.

17. Rubens FD, Rao RV, Chan V, Burwash IG. A matched-paired comparative analysis of the hemodynamics of the Trifecta and Perimount aortic bioprostheses. $J$ Heart Valve Dis. 2015;24:487-95.

18. Pibarot P, Dumesnil JG. Prosthesis-patient mismatch: definition, clinical impact, and prevention. Heart. 2006;92:1022-9.

19. Raghav V, Okafor I, Quach M, Dang L, Marquez S, Yoganathan AP. Long-term durability of Carpentier-Edwards Magna Ease valve: a one billion cycle in vitro study. Ann Thorac Surg. 2016;101:1759-65.

20. Higgins J, Jamieson WR, Benhameid O, Ye J, Cheung A, Skarsgard P, et al. Influence of patient gender on mortality after aortic valve replacement for aortic stenosis. J Thorac Cardiovasc Surg. 2011;142:595-601. e1-2.

21. Tabata M, Shibayama K, Watanabe H, Sato Y, Fukui T, Takanashi S. Simple interrupted suturing increases valve performance after aortic valve replacement with a small supra-annular bioprosthesis. J Thorac Cardiovasc Surg. 2014;147: $321-5$.

Key Words: aortic valve replacement, echocardiography, hemodynamics, outcomes, left ventricular mass regression 


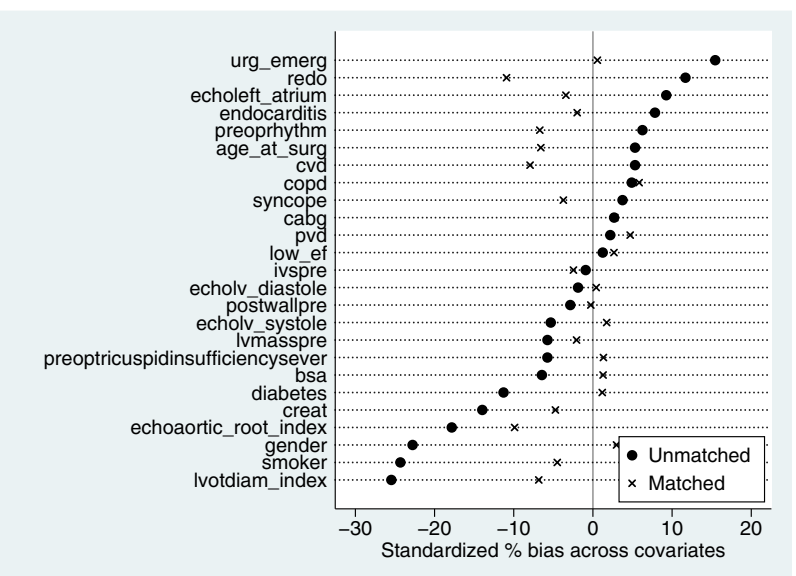

FIGURE E1. Summary of covariate imbalance (dots) with standardized bias for each covariate with correction (crosses).

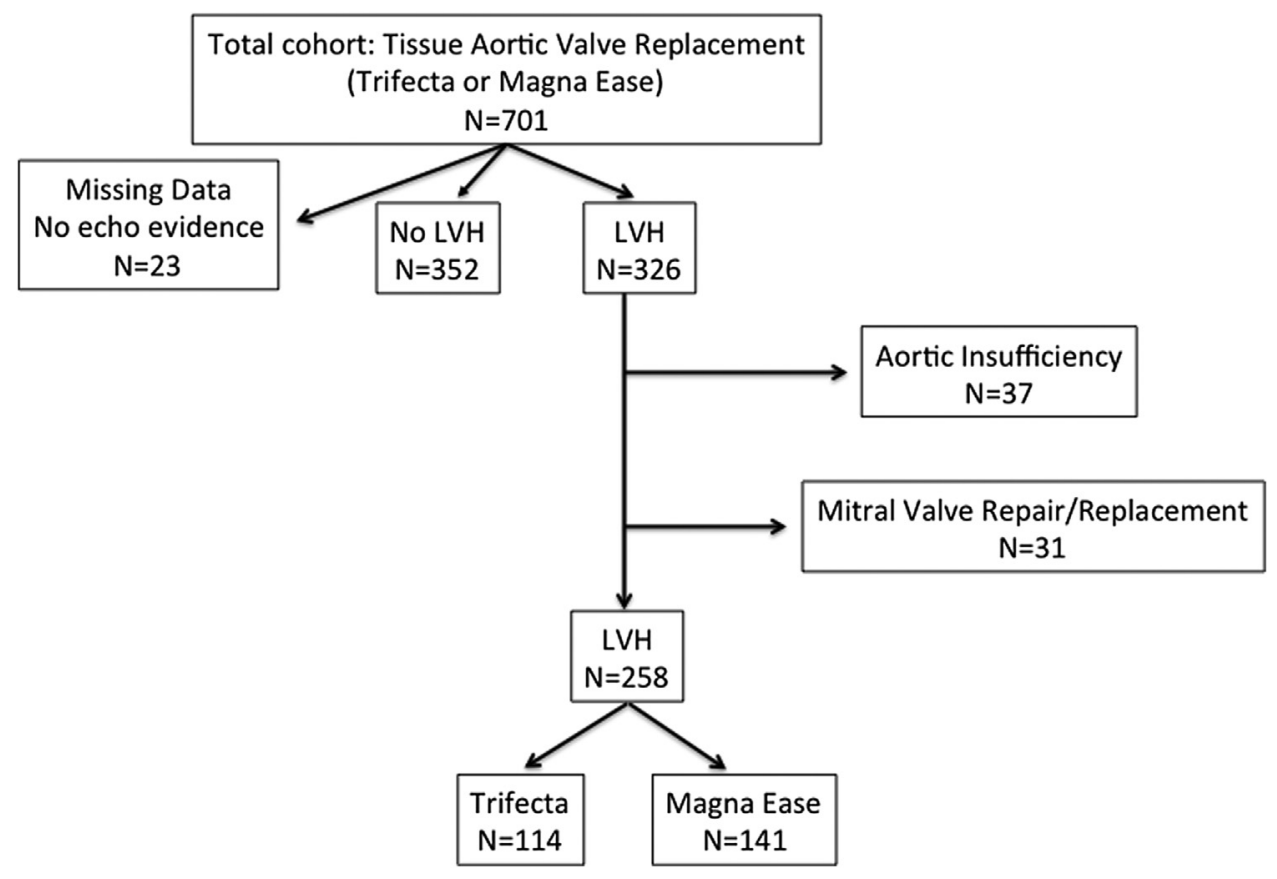

FIGURE E2. Patient enrolment algorithm. $L V H$, Left ventricular hypertrophy. 


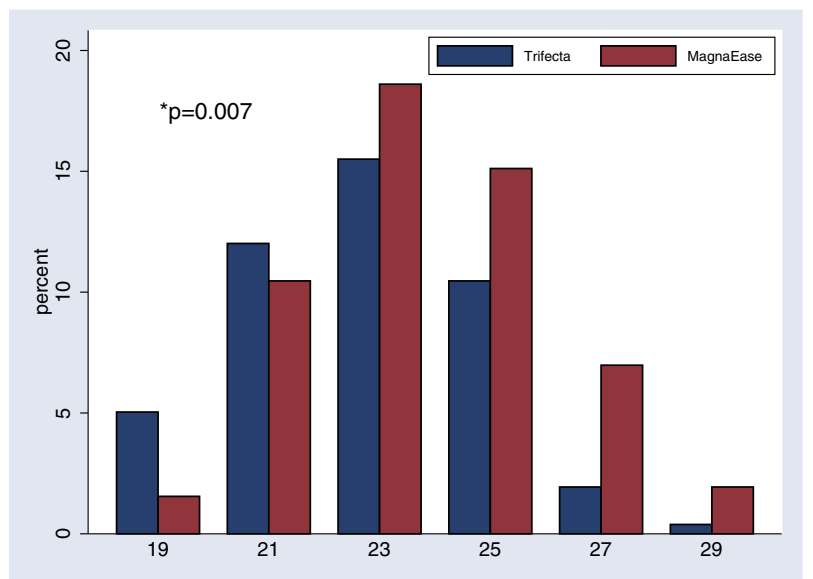

FIGURE E3. Distribution of valves sizes in the 2 groups. Significantly more smaller sized valves were in the Trifecta group.

TABLE E1. Early (ie, 30-day) postoperative outcomes

\begin{tabular}{|c|c|c|c|}
\hline Variable & $\begin{array}{l}\text { Trifecta } * \\
(\mathbf{n}=117)\end{array}$ & $\begin{array}{c}\text { Magna Ease } \dagger \\
(\mathbf{n}=\mathbf{1 3 7})\end{array}$ & $P$ value \\
\hline Atrial fibrillation & $20(17.1)$ & $28(19.9)$ & .570 \\
\hline $\begin{array}{l}\text { Embolism/cerebrovascular } \\
\text { accident }\end{array}$ & $2(1.7)$ & $7(5.0)$ & .156 \\
\hline Bleeding & $4(3.4)$ & $9(6.4)$ & .279 \\
\hline Tamponade & $0(0.0)$ & $4(2.8)$ & .066 \\
\hline Mortality & $1(0.9)$ & $5(3.6)$ & .156 \\
\hline
\end{tabular}

